Kansas State University Libraries

New Prairie Press

\title{
NEPOTISM IN HONEY BEES, COMPUTER PROGRAMS AND SCIENTIFIC HYPOTHESES
}

\author{
Benjamin P. Oldroyd \\ Thomas E. Rinderer
}

Follow this and additional works at: https://newprairiepress.org/agstatconference

Part of the Agriculture Commons, and the Applied Statistics Commons

\section{(c) (1) $\Theta(9$}

This work is licensed under a Creative Commons Attribution-Noncommercial-No Derivative Works 4.0 License.

\section{Recommended Citation}

Oldroyd, Benjamin P. and Rinderer, Thomas E. (1990). "NEPOTISM IN HONEY BEES, COMPUTER PROGRAMS AND SCIENTIFIC HYPOTHESES," Conference on Applied Statistics in Agriculture. https://doi.org/10.4148/2475-7772.1432

This is brought to you for free and open access by the Conferences at New Prairie Press. It has been accepted for inclusion in Conference on Applied Statistics in Agriculture by an authorized administrator of New Prairie Press. For more information, please contact cads@k-state.edu. 


\section{NEPOTISM IN HONEY BEES, COMPUTER PROGRAMS AND SCIENTIFIC} HYPOTHESES

Benjamin P. Oldroyd and Thomas E. Rinderer, United States Department of Agriculture, Agricultural Research Service. Honey-Bee Breeding, Genetics \& Physiology Research Laboratory, 1157 Ben Hur Rd., Baton Rouge, Louisiana 70820, USA.

Steven M. Buco, Statistical Resources, 7332 Highland Road, Baton Rouge, Louisiana, 70808, USA.

\section{Abstract}

Page et al. (1989) attempted to show that bees on queen cells preferentially reared their super sisters as replacement queens rather than half sisters. In support of their contention, they used computer simulation to model the biological system. We argue that the simulation did not accurately reflect the biological system in several important respects. We show that random data will produce the same kinds of statistical significance as the actual data.

Simulation - Monte Carlo Simulation - Honey bee - Kin recognition - Kin selection

\section{Introduction}

It is intuitively difficult to see how sterility could have evolved in the workers of the social hymenoptera. Hamilton's (1964 a b) inclusive fitness (kin selection) hypothesis provided a satisfying explanation. He pointed out that because of haplo-diploidy, hymenopteran females are more related to their sisters $(r=0.75)$ than to their own offspring $(r=0.5)$. Thus the reproductive success of workers can be increased by rearing sisters rather than offspring. However, Starr (1979) pointed out that the serious difficulty for this hypothesis is that for species like honey bees that are polyandrous, the average genetic relatedness of workers in a colony is not 0.75 but approaches 0.25 (i.e. most workers are half sisters). Such workers are more related to their own offspring than to most of their sisters. To maximize their inclusive fitness, they would be expected to invest more in offsprir:g than in sisters. The hypothesis was defended from Starr's criticism (Orlove 1975, Trivers \& Hare 1976) by recourse to an early paper by Taber (1955). He claimed to show that the sperm of each drone involved in a honey bee mating remains appreciably clumped in the spermatheca. If this were true, then at any one time, the queen would predominantly use the sperm of one drone, and would thus produce daughters most of which would be related to each other by 0.75. However, it was then shown (Crozier \& Brückner 1981, Page \& Metcalf, 1982) that the Taber data did not support his conclusions. Laidlaw and Page (1984) finally laid the sperm clumping defence to rest by demonstrating that offspring of each drone involved in a mating can be found at any one time.

Alternative support for kin selection in honey bees emerged when Getz (1981) pointed out that if the workers of each subfamily within a colony could recognize each other, they could increase their inclusive fitness by modifying their reproductive behavior. A number of experiments (Page \& Erickson 1986, Frumhoff \& Schneider 1987, Visscher 1986, 
Getz et al. 1982, Getz \& Smith 1983, Noonan \& Kolmes 1989, Evers \& Seeley 1986) then sought to discover the existence of kin recognition systems that would allow workers to discriminate super and half sisters. Most of these studies relied on detailed observations of worker interactions in colonies of two phenotypically distinct subfamilies. They present some evidence for kin recognition in honey bees, but do not demonstrate reproductive advantages consequent on such recognition.

Page et al's. elegant experiment attempted to show that honey bees can recognize their super sister larvae, and that some subfamilies dominate in queen-rearing and preferentially rear their super sisters as queens. This was done by establishing colonies with three biochemically distinct subfamilies. The authors then measured the relative frequency of each subfamily in a sample of queens raised by each colony, in a sample of adult workers taken from the area surrounding the queen cells, and in a sample of contemporaneous immature workers.

These data showed variability in the relative frequencies of each subfamily between each kind of sample. One explanation for this observation (supported by Page et al.) is that deviations in the subfamily relative frequencies were due to nepotism.

\section{The Analysis}

A Monte Carlo simulation procedure was devised by Page et al. in order to establish the sampling distribution of their experimental system and thereby test the statistical significance of their findings. Prior to simulation, the test subfamily for "nepotism" (defined as that subfamily which had the highest value of RLs = the frequency of the subfamily in adults found on queen cells / the frequency of the subfamily found in contemporaneous immature workers) was determined for each trial from the observed data. The deviation between the expected (based on immature workers) and observed frequency of this subfamily in queens was then determined, and summed for the 30 trials to produce a total deviation for the entire experiment. For each trial, the simulation commenced by specifying an infinite population, such that the relative frequencies of subfamilies equaled those estimated from the pooled frequencies found in the experimental immature workers and queens. A sample of size equivalent to that actually taken from the colony being simulated was then randomly drawn for immature workers, immature queens, and adult workers found on queen cells, from the simulated colony population. The test subfamily for the simulated trial was then determined as described above, and deviation in frequency of this test subfamily between queens and immature workers was then calculated. These calculations were made for 30 simulated trials, and the total deviation for the entire simulated experiment was then computed. The simulation was iterated 1000 times. The probability of getting simulated total deviations as extreme as those observed was estimated as the percentage of simulations in which the deviation equalled or exceeded the total deviation of +60 , that was observed in the actual field experiment. The null hypothesis, that the genotype of bees found on queen cells does not affect the genotype of queens produced, would be rejected at the $5 \%$ level, if less than $5 \%$ of the simulations produced an excess of 60 queens of the "nepotistic" subfamilies.

The reported results of the simulation show a highly significant result, supporting the nepotism hypothesis. We believe that this conclusion is a consequence of the interaction of two experimental deficiencies, and three discrepancies between the real world and the simulation methodology. The experimental deficiencies are the small sample sizes $(n=$. 
34:51), and the fact that 6 of the 10 experimental queens used were heterozygous for $\mathrm{MDH}$, necessitating, for several classes of genotype, allocation of subfamily affinity on the basis of probability determined from a subsample of the already small samples. Both these shortcomings mean that the relative frequencies of the three subfamilies in each colony is estimated with high sampling error for immature workers.

The first deficiency in the simulation methodology relates to the way the "test subfamily" is selected. For the real data, the wrong test subfamily will be allocated from time to time, because of high sampling error, and these will tend to be those for which the relative frequency was underestimated in immature workers, since such underestimation increases RLs, the apparent ratio of adult workers on queen cells to immature larvae. Subfamilies whose relative frequency has been overestimated in immature workers will tend to be erroneously excluded as test subfamilies, for similar reasons. Thus, sampling error tends, for the observed data, to cause test subfamilies which generate low expected values of relative frequency in immature queens, to be erroneously selected. This in turn leads (for these subfamilies) to large deviations in the observed and expected frequencies in immature queens. The deviation is reduced in the simulation where all queens are treated as homozygous, and all worker genotypes are known. Thus the wrong test subfamily will be chosen less often, due to reduced variance in estimates of subfamily relative frequency.

The second discrepancy stems from the larger sample size used in the simulations compared to the actual data. Variance of the simulated sampling distribution is therefore lower than that of the data's sampling distribution. In this context, sampling error alone will reduce deviations between observed and expected frequencies of queens in the simulated populations compared to the experimental data.

The third error is consequent on the fact that worker (unselected) and queen (selected) samples were pooled to provide estimates of population subfamily relative frequency for the simulation. (In contrast, expected values for the observed data were calculated on the basis of worker frequencies alone). The weighted average will inevitably be intermediate between the queen and worker sample relative frequencies, thereby reducing the apparent magnitude of deviations between relative frequencies in the computer generated queen and worker samples. Thus it is inevitable that the total deviation will appear higher for the observed data than in the simulation where pooled estimates of population relative frequency were used. In fact, if identical procedures are used for the observed data as were used for the simulation (i.e. queen relative frequencies are predicted from pooled worker + queen frequencies), then the total number of excess queens reared is -2 , indicating that no nepotism occurred.

\section{Testing the simulation's deficiencies}

The extent to which the pooling errors contribute to the statistical significance reported can be evaluated by applying the Page et al. methodology to random "data" that cannot logically support the nepotism or any other hypothesis. To produce these "data", we generated a large population of immature larvae and queens, and adult workers all with three subfamilies at equal frequency (0.33). The simulation then drew random samples of immature workers and queens, and adult workers, with sample and sub-sample sizes, and levels of replication identical to the reported experiment. Six hundred of these data sets were produced, and were then analyzed using the statistical procedure described by Page et al. Figure 1 shows the frequency distribution of these total deviations for the 600 
Figure 1. Nepotism in honey bees or computer programs?

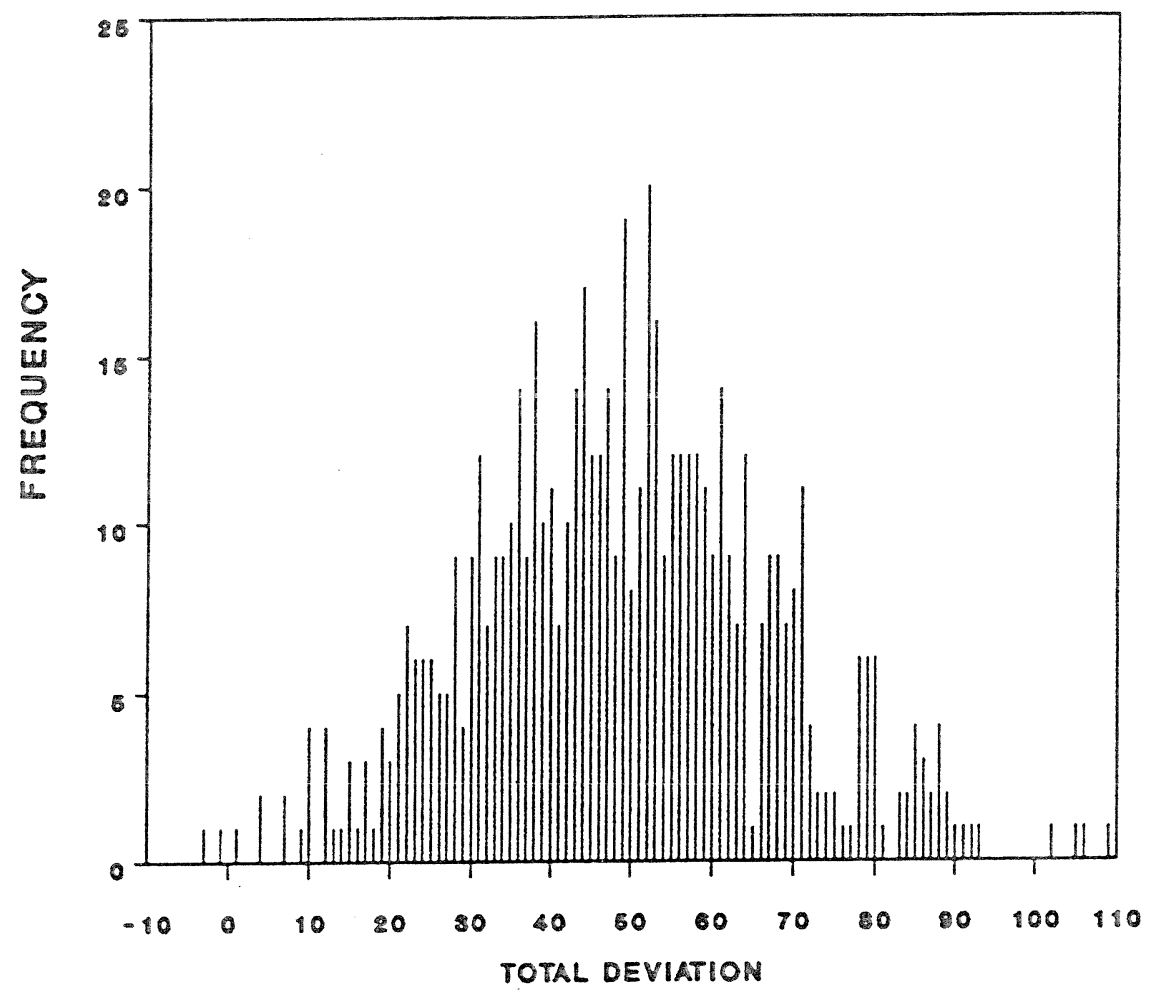

Simulation was used to generate 600 data sets each of 3 trials of 10 colonies composed of 3 sub-families at equal frequency. The frequency distribution of simulations which produced each deviation in "observed" and expected numbers of queens for nepotistic subfamilies is plotted. Page et al. observed a deviation of 60 queens for their experimental data. The figure shows that this is well within the range expected by chance. Data sets were also generated for colonies with differing subfamily relative frequency. The results obtained were similar to those in the figure.

simulated data sets. Page et al. observed a total deviation of +60 queens for their 30 trials. Twenty six per cent of our random data sets, drawn from a totally uniform non-nepotistic population, had total deviations which equalled or exceeded this deviation. This demonstrates that sampling error alone could often produce the results observed by Page et al.

We then "estimated the probability of getting a deviation that was as great or greater than our results", using the Page et al. Monte Carlo simulation. Eighty four per cent of our simulated data sets produced a "significant" deviation. 
Table 1. Cochran-Mantel-Haenszel tests of general association ( 2 d.f.) in subfamily relative frequency between immature workers and queens. Data of Page et al.

$\begin{array}{llllll}\begin{array}{l}\text { Colony } \\ \text { number }\end{array} & \chi^{2} & P & \begin{array}{l}\text { Colony } \\ \text { number }\end{array} & \chi^{2} & P \\ 4438 & 0.36 & 0.55 & 4450 & 4.15 & 0.06 \\ 4439 & 3.76 & 0.15 & 4453 & 0.60 & 0.74 \\ 4440 & 0.95 & 0.62 & 4456 & 1.85 & 0.40 \\ 4442 & 0.30 & 0.86 & 4457 & 1.48 & 0.48 \\ 4445 & 1.97 & 0.37 & 4464 & 0.71 & 0.70\end{array}$

Contrary to the argument of Page et al. concerning finite population sizes, Cochran-Mantel-Haenzel tests of general association were performed to compare subfamily relative frequencies in unselected workers and "selected" queens (Fleiss, 1981). The Cochran-Mantel-Haenzel test allows valid pooling across trials. No colonies showed significant deviations in subfamily ratios between immature workers and queens, indicating no rearing preference.

We conclude that even with data drawn from a population in which subfamily frequencies are uniform, that biases in the statistical procedure used produce spurious statistical significance. Thus the nepotism hypothesis is likely to be supported, whatever data are used. However, in our view, Page et al.'s data, rather than being neutral, strongly suggest that nepotism did not occur in their experiments. First, there is no evidence that subfamily relative frequencies differed significantly between workers and queens (when trials are pooled) which they should if selective rearing did occur. Cochran-Mantel-Haenszel tests of general association (computed from pooled actual trial data) are presented in Table 1. They show no significant deviations in subfamily relative frequency between worker larvae and queen pupae. Thus this statistic does not support the nepotism or other hypotheses proposed by Page et al.

Second, the test subfamilies are theorized to be genetically predisposed to rear queens. However, the data (not presented) show that test subfamily identity varied substantially among trials within colonies, suggesting that genetic determination of such specialization did not exist among the subfamilies of the experimental colonies.

\section{Conclusions.}

Experimental support for subfamily nepotism in honey bees continues, as it historically has done, to be equivocal. Only when an experiment links subfamily recognition to substantive reproductive advantages will this hypothesis be supported.

The deficiencies in the paper by Page et al. emphasize the need for extreme caution when using simulation to test the significance of scientific hypotheses. There must be good reason for not using conventional statistics. When establishing the simulation it is essential that like be compared with like. The sampling distribution and sample sizes used in both the simulation and the sample data must be identical. If identity of treatments is associated 
with a sampling error, then this error must be incorporated into the simulation.

Acknowledgements

A summary of this paper appeared in Nature (Oldroyd et al. 1990). We thank Dr. R.E. Page for most graciously sharing his data with us. Drs. R. Crozier, J. Harbo and G. Milliken made valuable suggestions on the drafts of this paper.

\section{REFERENCES}

Crozier, R.H. \& Brückner, D. (1981) Sperm clumping and the population genetics of Hymenoptera Am. Nat. 117 : 561-563.

Evers, C.A. \& Seeley, T.D. (1986) Kin discrimination and aggression in honeybee colonies with laying workers. Anim. Behow. 34 : 924-925.

Fleiss, J.L. (1981) Statistical methods for ratios and proportions. J. Wiley, New York. pp 173-175.

Frumhoff, P.C. \& Schneider, S. (1987) The social consequences of honey bee polyandry: the effects of kinship on worker interactions within colonies. Anim. Behav. $35: 255-262$.

Getz, W.M. (1981) Genetically based kin recognition systems. J. Theoret. Biol. 92, 209-226.

Getz, W.M., Brückner, D. \& Parisian, T. (1982) Kin structure and the swarming behavior of the honeybee Apis mellifera. Behav. Ecol. Sociobiol. $10: 265-270$.

Getz, W.M. \& Smith, K.B. (1983) Genetic kin recognition: Honey bees discriminate between full and half sisters. Nature $302: 147-148$.

Hamilton, W.D. (1964 a) The genetical evolution of social behavior. I. J. Theoret. Biol. 7 : 1-16.

Hamilton, W.D. (1964 b) The genetical evolution of social behavior. II. J. Theoret. Biol. 7 : $17-52$.

Laidlaw, H.H. \& Page, R.E. (1984) Polyandry in honey bees (Apis mellifera L.) : sperm utilization and intracolony genetic relationships. Genetics $108: 179-188$.

Noonan, K.C. \& Kolmes, S.A. (1989) Kin recognition of worker brood by worker honey bees Apis mellifera. J. Ins. Behav. $2: 473-485$.

Oldroyd B.P., Rinderer, T.E. \& Buco, S.M. (1990) Nepotism in honey bees. Nature 346 : 707-708.

Orlove, M.J. (1975) A model of kin selection not invoking coefficients of relationship. $J$. Theoret. Biol. 49 : 289-310. 
Page, R.E. \& Metcalf, R.A. (1982) Multiple mating, sperm utilizations and social evolution. Am. Nat. $119: 263-281$.

Page, R.E. \& Robinson, G.E. \& Fondrk, M.K. (1989) Genetic specialists, kin recognition and nepotism in honey-bee colonies. Nature $338: 576-579$.

Starr, C.K. (1979) Origin and evolution of insect sociality. A review of modern theory. In H.R. Hermann, ed. Social Insects. Vol. 1. pp. 35-79. (Academic Press, London).

Taber, S. (1955) Sperm distribution in the spermathecae of multiple mated queen honeybees. J. Econ. Ent. 48 : 322-525.

Trivers, H.R. \& Hare R.H. (1976) Haplodiploidy and the evolution of social insects. Science $191: 249-263$.

Visscher, P.K. (1986) Kin discrimination in queen rearing by honey bees (Apis mellifera). Behav. Ecol. Sociobiol. 18 : 453-460. 